\title{
EXPERIÊNCIA E VIVÊNCIA, PERCEPÇÃO E CULTURA: UMA ABORDAGEM DIALÉTICA DAS MANIFESTAÇÕES CULTURAIS EM BAIRROS POPULARES DE SALVADOR-BAHIA
}

\author{
Cognitive experience and immediate apprehension, perception and culture: a \\ dialectical approach of cultural markers at popular neighborhoods in the suburb \\ of Salvador municipality, Bahia State.
}

\author{
Angelo SERPA ${ }^{1}$
}

\begin{abstract}
RESUMO
Neste artigo, busca-se analisar os processos culturais de três bairros populares de Salvador, Bahia. Especial atenção é dada à análise do papel da cultura na vida social dos moradores, baseando-se em contribuições de Walter Benjamin, Hannah Arendt, Jürgen Habermas e Pierrre Bourdieu assim como em entrevistas estruturadas realizadas com residentes dos bairros. As manifestações culturais foram analisadas como proposto por Denis Cosgrove (que as classifica como dominantes, residuais, emergentes ou excluídas), a fim de explicitar as diferentes formas de manifestação da cultura popular ainda presentes nos bairros estudados, enfatizando, na análise, o confronto entre cultura popular e cultura oficial. Os resultados mostram que os bairros populares transformamse em microcosmos, com suas manifestações culturais e práticas sociais próprias, que representam muitos interesses (políticos, comerciais, promocionais, etc.), restando, como diferencial, os interesses das associações de bairro, que realizam atividades culturais em prol da preservação e manutenção de sua tradição e identidade.
\end{abstract}

\section{Palavras-chave:}

Bairro, identidade cultural, manifestações culturais.

\begin{abstract}
This article explores the analysis of cultural processes at three neighborhoods in the suburb of Salvador, Bahia. Consideration is given to the role of culture in inhabitants' social life on the basis of the contributions made by Walter Benjamin, Hannah Arendt, Jürgen Habermas and Pierrre Bourdieu as well as of structured interviews accomplished with residents of the suburb of Salvador. The cultural manifestations were examined as proposed by Denis Cosgrove (classified as dominant, residual, emergent or excluded) to bring forth new information about the different types of popular culture and to emphasize the confrontation between popular and official culture. The results have shown that neighborhoods become microcosms with their own cultural manifestations and social rules, that represent many interests (political, commercial, promotion, etc.), remaining, as a differential, the interests of the neighborhood associations, that accomplish cultural activities on behalf of the preservation and maintenance of their tradition and identity.
\end{abstract}

\section{Key-words:}

Neighborhood, cultural identity, cultural manifestations.

1 Professor Adjunto Doutor do Departamento e Mestrado de Geografia da Universidade Federal da Bahia, bolsista de produtividade em pesquisa do CNPq. E-mail: angserpa@ufba.br 


\section{INTRODUÇÃO}

Discutir a percepção de "cultura" nos bairros populares de Salvador parece, a princípio, tarefa ingrata e complexa, em um momento de transformações evidentes da paisagem da cidade para o consumo turístico. Qual o impacto dessas estratégias econômicas nas manifestações culturais e na percepção de cultura nos bairros populares de Salvador? O que se entende, afinal, por cultura nas áreas de urbanização popular da cidade?

O objetivo aqui é ampliar ao máximo a formulação de um conceito de cultura que abarque as representações e práticas sociais dos bairros populares da cidade contemporânea, evidenciando as características e as possíveis peculiaridades das manifestações culturais nestes "lugares". ${ }^{2}$ Propõe-se uma abordagem "social" da cultura popular, não esquecendo os aspectos culturais das práticas e representações sociais, objetivando uma análise dialética das relações existentes entre sociedade e cultura. ${ }^{3}$

A relação entre cultura e poder está na base da análise das manifestações inventariadas nos bairros pesquisados. A cultura é vista aqui como um motivo de conflito de interesses nas sociedades contemporâneas, um conflito pela sua definição, pelo seu controle, pelos benefícios que assegura (SANTOS, 1988). Cultura (palavra e conceito) é de origem romana, significava originalmente agricultura, tida em alta conta na Roma antiga em oposição às artes plásticas e ao fabrico. Também exprimia a reverência romana para com o testemunho do passado (preservação do legado grego e continuidade da tradição). Mesmo no presente, cultura ainda é pensada nos termos de tornar a natureza um lugar habitável para as pessoas e de cuidar dos monumentos do passado. Mas isso não esgota os significados da palavra, do conceito de cultura (Compare: ARENDT, 2002).

Nos bairros populares das metrópoles capitalistas são os moradores os verdadeiros agentes de transformação do espaço. Eles articulam-se em "rede", não uma rede única, mas redes superpostas, conforme o tema que se esteja enfocando. Temos que diferenciar, por exemplo, os tópicos específicos dos jovens, das mulheres casadas, os tópicos dos homens adultos, etc., em cada lugar concreto, e também diferenciar os tópicos das etnias, nas diversas formas em que podem se apresentar suas culturas e subculturas (Compare: VILASSANTE, 1996).

A questão da imagem/identidade dos bairros vem sendo trabalhada, em pesquisa financiada pelo CNPq, baseando-se em levantamentos qualitativos com um universo restrito de entrevistados em três bairros populares da capital baiana: ${ }^{4}$ Plataforma ${ }^{5}$ (no Subúrbio Ferroviário de Salvador), Ribeira ${ }^{6}$ (na Península de

2 Os lugares clamam nossas afeições e obrigações, conhecemos o mundo através dos lugares nos quais vivemos. Lugares são existenciais e uma fonte de autoconhecimento e responsabilidade social (RELPH, 1979).

3 "A ênfase atual dedicada à criatividade cultural e à cultura como uma força ativa na história precisa ser acompanhada por alguma noção dos limites e restrições nos quais essa criatividade se manifesta. Em vez de simplesmente substituir a história social da cultura pela história cultural da sociedade, faz-se necessário trabalhar com as duas idéias de forma conjunta e simultânea, independentemente do grau de dificuldade que isso possa acarretar. Em outras palavras, parece-nos bem mais proveitoso considerar a relação entre cultura e sociedade em termos dialéticos com ambas as partes, a um só tempo, ativas e passivas, determinantes e determinadas" (BURKE, 2002, p. 171).

4 Trata-se do projeto integrado de pesquisa "Identidade de Bairro nas Periferias Urbanas (Projeto Espaço Livre)": A partir de agosto de 2000, passamos a testar uma nova metodologia de levantamento de dados empíricos em alguns dos bairros estudados (Plataforma e Ribeira, num primeiro momento, e Curuzú, a partir de agosto de 2003), baseada em conceitos e procedimentos da Fenomenologia e da Geografia Humanística e da Percepção, visando à qualificação dos levantamentos realizados nos anos anteriores de pesquisa nas áreasestudo e sua possível aplicação no processo de planejamento. Estas pesquisas foram desenvolvidas entre os anos de 2000 e 2002 por duas bolsistas de iniciação científica, no âmbito do PIBIC-UFBA: Suely dos Santos Coelho e Márcia de Freitas Cordeiro, nos bairros de Plataforma e Ribeira; no Curuzú, a pesquisa foi realizada por Flávia Silva de Souza, estudante de Geografia e bolsista de iniciação científica do CNPq, em 2003/2004. Desde maio de 2003, estamos retomando as atividades nos três bairros, com grupos interdisciplinares de estudantes da UFBA, monitorados por Marcelo Sousa Brito, estudante do curso de bacharelado em direção teatral (UFBA) e bolsista de extensão da FAPESB/PROEX-UFBA, para realização da atividade curricular em comunidade "O Bairro em Imagens" (GEO 458, disciplina do curso de Geografia). A partir da organização de um banco de imagens audiovisuais, com a edição de vídeos-documentário (um para cada bairro), pretende-se retornar às comunidades os resultados da pesquisa, com a organização de debates em escolas públicas e nas associações de moradores, a partir da exibição do material audiovisual editado. Pretende-se também que os vídeos realizados sirvam de subsídio didático para os professores de Geografia e História das escolas públicas existentes nos bairros pesquisados.

${ }^{5}$ Situado no Subúrbio Ferroviário, Plataforma é um dos bairros mais antigos dessa região. Os primeiros núcleos de indústria têxtil se estabeleceram na Bahia por volta de 1844 e, em Plataforma, em 1875. Também é do século XIX (1850) a instalação de ampla rede ferroviária no Brasil e em particular na Bahia, ligando Salvador ao interior e entrecortando Plataforma. Ao lado da estação ferroviária localiza-se o terminal hidroviário (desativado), antiga ligação do bairro com a Ribeira, que tem sua história também ligada à indústria têxtil (SERPA e GARCIA, 1999, p. 97-98).

${ }^{6}$ Primitivamente, a Ribeira - expressão portuguesa que significa ancoradouro de reparação de naus - era uma colônia de pescadores e lugar de veraneio, muito distante do centro da cidade, cuja única via de acesso era o mar. Com a construção da basílica do Bomfim, a península de Itapagipe passou a receber romeiros de vários pontos da cidade, que passavam ali longas temporadas. O bairro da Ribeira está localizado a noroeste do município. A população do bairro é constituída em sua maioria por famílias com renda mensal de até 03 salários mínimos. O bairro caracterizou-se como industrial, a partir da implantação de diversas fábricas. Após o fechamento destas, intensificaram-se as funções residenciais e comerciais (COELHO e SERPA, 2001,p. 110). 
Itapagipe), e Curuzú7 (no miolo de Salvador). Trabalhase o conceito de redes como instrumental para seleção e amostragem dos entrevistados, geralmente partindose das redes formais/associativistas (com maior visibilidade), como associações de moradores, clubes de mães, templos religiosos, identificando seus portavozes e buscando-se caracterizar suas estratégias de ação e formas de organização, bem como a interação entre eles. O passo seguinte é a identificação das redes informais/submersas, como grupos de jovens, de terceira idade, redes de vizinhança e parentesco, "pinçando-se" também desse universo os porta-vozes dos diferentes grupos identificados.

Para definição do universo de entrevistados em cada bairro pesquisado (19 na Ribeira, 24 em Plataforma e 21 no Curuzú) foram levados ainda em consideração fatores como sexo, faixa etária, local e tempo de moradia no bairro. Com base na realização de entrevistas com moradores das áreas pesquisadas, pretendeu-se explicitar o entendimento e a imagem que se tem do bairro enquanto conceito (construção mental), já que concorda-se aqui com TUAN (1983) de que o conceito pode ser deduzido e esclarecido por meio de perguntas, dirigidas primeiro para o concreto e depois para o mais abstrato.

Através de técnicas de cartografia cognitiva, com a identificação dos referenciais arquitetônicos, percursos, limites etc., consolidados na percepção dos moradores, busca-se a construção de uma representação coletiva para cada bairro, a partir das representações individuais (identificando-se os pontos comuns entre as diferentes representações). Segue-se a ordem/sucessão "meu" (representação individual), "nosso" (representação coletiva de nível intermediário, específica para cada grupo - formal ou informal) e "o" bairro (representação coletiva de nível superior) - Compare: TUAN (1983).

Nas entrevistas qualitativas com os moradores foi dada especial atenção às festas e comemorações nos bairros pesquisados: O que você entende por "cultura"? O que há, na sua opinião, em termos de manifestações culturais em seu bairro? Como eram essas manifestações no passado? Algo mudou? Final-mente, a pesquisa buscou também avaliar como a mídia impressa registra essas manifestações, a partir da consulta aos arquivos dos maiores jornais de circulação diária em Salvador, nas duas últimas décadas.

\section{CULTURA DE BAIRRO}

A Geografia Urbana clássica contentava-se em estabelecer o bairro como uma noção dada a priori ao pesquisador, enfatizando a relação do sítio (meio físico) com a evolução da ocupação humana. Mesmo o aparecimento das análises sobre a vivência e a percepção do bairro, no campo da Geografia da Percepção e do Comportamento, "representou pouco mais que uma simples transmutação de interesses sem ruptura com a tradição do acriticismo e pouca profundidade" (SOUZA, 1989).

Dialetizar as relações entre sociedade e cultura olhando o bairro como o lugar da experiência pode ajudar na busca de instrumentos teórico-conceituais mais flexíveis que aqueles legados pela Sociologia Culturalista, para melhor entender a problemática do "bairro" no contexto da metrópole capitalista, como propõe souzA, 1989, evitando apriorismos e petrificações conceituais.

As relações de vizinhança constituem um caso particular de "redes do cotidiano". Elas são ainda muito condicionadas pelas diferenças entre classes sociais. Nos bairros populares, a limitação de oportunidades, a pobreza e o isolamento relativos, a insegurança e o medo acabam por fortalecê-las e torná-las parte fundamental da trama de relações familiares (KELLER, 1979):

Eu percebo que é um bairro privilegiado porque as pessoas que moram aqui têm a sensação de que aqui é um interior, interior da cidade, porque as pessoas aqui sentam na porta para conversar, se você passar aqui às 5 horas da tarde, você vai encontrar algumas pessoas que têm esse costume, então é um bairro que inspira confiança, diante de tanta violência que percebemos hoje no nosso dia-a-dia, por ser um bairro com estas características eu acredito que seja privilegiado. $^{8}$

Nos bairros de classe média, as relações entre vizinhos são mais seletivas e pessoais e, na maior parte dos casos, o maior poder aquisitivo faz diminuir a necessidade de ajuda mútua e aumentar a necessidade individual de espaço (KELLER, 1979):

\footnotetext{
Também aqui na Ribeira nós temos o costume de "sentar na porta", tomar fresco, que a gente não vê em outros bairros. Em canto nenhum na cidade. Tem gente que mora num lugar que não conhece ninguém;
}

7 O Curuzú possui uma população de baixa renda e sofre com muitos problemas de infra-estrutura urbana. A sua história está relacionada à história do bairro da Liberdade que, na segunda metade do século XIX, era conhecido como Estrada da Boiada, por onde passavam os animais que eram levados para o matadouro do Retiro. O Curuzú surgiu da necessidade de novos espaços para habitação: os moradores passaram a arrendar as terras da família Martins Catharino, construindo suas casas e promovendo o lento crescimento do bairro. Algumas famílias estão no lugar há mais de um século (SOUZA, 2004).

8 João Carlos de São Pedro, morador do bairro da Ribeira. 
aqui é diferente. Aqui na rua mesmo, é como se fosse uma família, todo mundo unido e quando um tem uma coisa, todo mundo tá junto, entendeu ${ }^{9}$

Mas, o bairro é mais que um coeso agregado de unidades de vizinhança. TUAN (1983) explica que a rua onde se mora é parte da experiência íntima de cada um, mas a unidade maior, o "bairro", é um conceito. Não se expande automaticamente o sentimento que se tem pela rua local para todo o bairro. O conceito depende da experiência, mas não é uma conseqüência inevitável da experiência, já que o "bairro" só adquire visibilidade e torna-se um "lugar" através de um esforço da mente:

São dois morros, um é o bairro de Plataforma e o outro é o Alto de Terezinha, o risco no meio é a Avenida Suburbana que divide os bairros de Plataforma e Terezinha. Na Suburbana, a gente pode ver uma paisagem bonita que dá para ver o centro da cidade, o Comércio, a Ribeira, pro lado da ponte que passa o trem. Aqui é o mar (o entrevistado indica no desenho), que vem abrangendo isto tudo, e aqui é um monte de casas, na Ribeira. ${ }^{10}$

Cotidiano e vida de bairro são processos dinâmicos que ganham conteúdos diversos à medida que mudam as estratégias dos diferentes agentes que produzem esses espaços. Vale ressaltar nesse contexto que é no sistema de relações com o que lhe é externo, ou seja, com a alteridade, que a territorialidade pode ser definida. Ela está impregnada de laços de identidade, que tentam de alguma forma homogeneizar esses territórios, dotálos de uma área/superfície minimamente igualizante, seja por uma identidade territorial, seja por uma fronteira definidora de alteridade (HAESBAERT, 1997).

Os bairros têm diversas espécies de fronteiras: algumas são fortes, definidas e precisas, outras podem ser ligeiras ou incertas. No entanto, estes limites parecem desempenhar um papel secundário na sua constituição, embora possam fixar suas fronteiras e reforçar sua identidade (Compare: LYNCH, 1990):

Quando eu me lembro do Curuzú, lembro também das pessoas que passaram pelo Curuzú e que hoje eu olho pro lado, olho pro outro, encontro poucos com quem eu convivi, hoje estão morando em outros lugares, como Cajazeiras, Mussurunga. Na verdade o que eu acho importante aqui são as pessoas. ${ }^{11}$

\section{CULTURA DA EXPERIÊNCIA E DO CULTO}

De acordo com SEABRA (2003), os tempos de reza e de festa são elaborações socioculturais que unem aspectos sagrados e profanos da "vida de Bairro", primeiro sob o comando da Igreja e, mais tarde, sob o primado da ordem pública, modo pelo qual o Estado foi definindo sua inserção na sociedade. Analisando a evolução do bairro do Limão em São Paulo, a autora conclui que embora a reza e a festa não estivessem originalmente muito separadas, com o passar do tempo tenderiam a afastar-se. Ambas constituíam os fundamentos dos modos de ser da cultura rústica, ${ }^{12}$

que era essencialmente singela nos costumes e nos hábitos, porém portadora de uma simbologia ritual capaz de preencher e organizar a vida, inscrevendo-a numa seqüência rítmica de atos em conformidade com o calendário religioso (SEABRA, 2003, p. 232).

Religiosidade e festividade são, portanto, qualidades interligadas, dialeticamente inter-relacionadas, representando e condicionando também a gênese da maior parte das manifestações culturais dos bairros populares de Salvador:

Tem uma lavagem, todo ano, em janeiro, no dia 30. É a lavagem da praça São Brás, do santo padroeiro aqui do bairro. Tem muito tempo que essa lavagem do largo acontece, os devotos fazem essa caminhada aqui pelo bairro, em procissão, levando o santo. ${ }^{13}$

Se o catolicismo popular é muito presente nos bairros estudados, também as tradições afro-brasileiras são determinantes para o surgimento de manifestações culturais singulares:

Não precisei sair do Curuzú para encontrar uma família, essa família já estava aqui e é o terreiro de Mãe Hilda Jitolu. Após minha entrada no terreiro,

${ }^{9}$ Cleonice Simões Coelho dos Santos, moradora do bairro da Ribeira.

${ }^{10}$ Ronaldo Antônio da Conceição, morador de Plataforma, explicando os limites do bairro, durante a confecção do mapa mental solicitado na entrevista.

${ }^{11}$ Carlos Cruz da Conceição (vulgo Piloto), morador do bairro do Curuzú.

12 "Houve um tempo de reza e de festa no Bairro do Limão, com banda no coreto da lgreja, com procissões, quermesses quase todos os anos e com gente que vinha de longe. Tinha ainda o Açucena, clube com o time de futebol mais querido da várzea de São Paulo, segundo dizem os velhos moradores do Limão" (SEABRA, 2003, p. 232).

${ }^{13}$ Roque Souza, morador do bairro de Plataforma. 
aprendi uma identidade religiosa, aprendi a minha história, de onde eu vim, e para onde eu vou. E também o llê Aiyê, ${ }^{14}$ que me dá condições de apren-dizado, de capacidade para estar discutindo, aprendendo e fazendo esse intercâmbio com o próximo. Então família, religião e o llê Aiyê têm uma representatividade muito grande para mim. $^{15}$

As festas e as tradições religiosas pertencem à esfera da experiência, constituindo-se das impressões que o psiquismo incorpora na memória, das excitações que jamais se tornaram conscientes e que, transmitidas ao inconsciente, deixam nele traços mnêmicos duráveis. Memória individual e coletiva fundem-se nas sociedades tradicionais através da festa e do culto, onde episódios significativos do passado coletivo são rememorados,

permitindo a cada indivíduo incorporar essas memórias à sua própria experiência, e recordar-se delas, ao mesmo tempo que recorda seu próprio passado. Os dias festivos se destinam a provocar conscientemente essas reme-morações, e nesse sentido pertencem ao domínio da memória involuntária (ROUANET, 1987, p. 49).

Mas a incorporação dos bairros populares da cidade ao processo de produção capitalista vai produzir mudanças evidentes, incluindo o desaparecimento gradual da experiência, privando os moradores de sua história e da capacidade de integrar-se numa tradição, já que a experiência é matéria de tradição, onde memória individual e coletiva se fundem (Compare: ROUANET, 1987):

Tem a Segunda-Feira da Ribeira, que ocorre depois do Domingo do Bomfim, em janeiro, todo ano, e dura apenas um dia. Antigamente tinha a Terça-Feira Gorda. Pra nós, moradores do bairro, era melhor, porque não tinha muita gente. E a segunda era feriadão, não é mais. O povo que vem de manhã é o povo que não trabalha, mas o povo que trabalha chega à tarde, aí fica muito cheio. Antigamente era uma festa gostosa, hoje não é mais. ${ }^{16}$

BENJAMIN (1996) viu nisso tudo um "violento abalo da tradição", que se relaciona intimamente com os movimentos de massa de nossos dias. Deste modo, retira-se os objetos culturais de seu invólucro, destruindo-se sua aura. E, no momento em que os critérios da autenticidade e da unicidade deixam de aplicar-se à produção cultural, toda a função social desta produção se transforma. No mundo massificado do capitalismo atual, o homem tem um tipo de percepção voltado para o idêntico e para o contato direto com as coisas, o que exclui a unicidade e a distância que definem a aura (Compare: ROUANET, 1987 e BENJAMIN, 1996):

Na cidade baixa tem muito grupo de música. Eu tenho um irmão que tem uma banda de reggae. Na adolescência dele, começou a vir essa onda de música, aí eles começaram a formar uma banda. Tem grupo de pagode, reggae, axé. É o que está agora em evidência e aí todo mundo faz. ${ }^{17}$

Baseado na dicotomia freudiana que opõe a consciência à memória, BENJAMIN (1996) trabalha com uma nova dicotomia que opõe a vivência à experiência. Pertencem à esfera da vivência aquelas impressões cujo efeito de choque é interceptado pelo sistema percepçãoconsciência, que se tornam conscientes, e que, por isso mesmo, desaparecem de forma instantânea, sem se incorporarem à memória. Esta leitura da teoria freudiana do choque constitui uma das chaves para a compreensão da crítica cultural de BENJAMIN, já que, para ele, o mundo moderno se caracteriza pela intensificação das situações de choque, em todos os domínios (Compare: ROUANET, 1987 e BENJAMIN, 1996).

\section{CULTURA DA VIVÊNCIA E DA EXPOSIIÇ̃̃O}

A sobrevivência na cidade exige uma atenção superaguçada, a fim de afastar as múltiplas ameaças a que está sujeito o passante. A experiência do choque acaba produzindo um novo tipo de percepção, uma nova sensibilidade, concentrada na interceptação e na neutralização do choque, em contraste com a sensibilidade tradicional, que podia defender-se, pela consciência, contra os choques presentes, mas podia também, pela memória, evocar as experiências sedimentadas em seu próprio passado e na tradição coletiva (Compare: ROUANET, 1987 e BENJAMIN, 1996):

\footnotetext{
${ }^{14}$ A movimentação dos negros baianos em épocas mais recentes e com características e reivindicações novas e atualizadas, tem como seu ponto de partida a criação, em 1974, do bloco afro llê Aiyê, no Curuzú, desenvolvendo-se com o Movimento Negro Unificado (MNU) na segunda metade da década de 1970: "Reflexo de uma necessidade histórica de organização em torno de uma identidade étnica, o llê já surge com a proposta de ter apenas negros entre seus componentes" (DANTAS, 1996, p. 155).

${ }^{15}$ Ramnsés Santos dos Santos, morador do bairro do Curuzú.

${ }^{16}$ Cleonice Simões Coelho dos Santos, moradora do bairro da Ribeira.

${ }^{17}$ Mauritânia Macedo Teixeira, moradora do bairro da Ribeira.
} 
O que eu posso constatar pelos percursos que eu faço no bairro, é que os motoristas não obedecem a sinalização, não param quando devem parar, eu já fiquei mais de meia hora só para atravessar a Avenida Lima e Silva, porque os motoristas não deixavam, o grande número de camelôs na Lima e Silva nos obriga a usar a via pública no nosso trajeto como pedestre e aí tem que ficar no zig-zag. Muitos carros estacionam no passeio, então fica difícil. ${ }^{18}$

Enquanto os processos de apropriação e produção do espaço urbano superpõem cada vez mais a vivência à experiência, provocando o isolamento dos indivíduos e impossibilitando a relação de troca com o outro, os objetos culturais se emancipam do seu uso ritual, aumentando as ocasiões para que sejam expostos (Compare: ROUANET, 1987 e BENJAMIN, 1996):

Bom, nós temos musicalidade, nos Alagados temos alguns grupos de percussão e temos também trabalhos de coreografia. Aqui tem um ponto de referência como show, o Clube de Regatas Itapagipe. Ele sempre promoveu alguns eventos e, inclusive, o Grupo É o Tchan nasceu de apresentações feitas neste clube. Então o grupo foi amadurecendo e acabou conhecido nacionalmente. ${ }^{19}$

Segundo BENJAMIN, a exponibilidade dos objetos culturais cresceu em tal escala, com os vários métodos de sua reprodutibilidade técnica, que de uma prepon-derância absoluta do valor de culto na pré-história passou-se a uma preponderância absoluta hoje conferida a seu valor de exposição (Compare: BENJAMIN, 1996). Ao analisarmos, por exemplo, o tratamento dado pela imprensa escrita às manifestações culturais nos bairros populares pesquisados, percebe-se que, sob a ótica da mídia impressa, a Festa da Ribeira apresentou sinais de decadência e auge ao longo das duas últimas décadas. É importante, no entanto, compreender que o resgate de sua importância se deu através do trio elétrico - da música de carnaval.
A festa, na sua origem, nunca foi palco para esse aparato tecnológico. É compreensível, nas falas dos moradores, que apenas três deles tenham citado a festa, sendo que o mais jovem foi o único que a relatou com algum entusiasmo. ${ }^{20} \mathrm{~A}$ "aura" sempre esteve ligada a um ritual ou a um artifício religioso, através de objetos autênticos, únicos, que chegavam ao homem através de estímulos emocionais. Desse modo, pressupõe-se que a festa popular, na Ribeira, possa conter também a sua "aura", pois se iniciava com um ritual religioso, seguido da parte profana. ${ }^{21}$ Ao longo dos anos, a "aura" da festa, antes sobretudo vinculada ao aspecto religioso, praticamente desapareceu. Hoje, o seu acontecer é marcado pela realização do lucro e pela possibilidade da diversão e do lazer (Compare: CORDEIRO e SERPA, 2002; CORDEIRO, 2001).

A "aura" dos objetos culturais desaparece, portanto, para abrir um espaço onde se instala uma nova "aura": a da mercadoria, cujo fetichismo suscita no consumidor/usuário/turista uma atitude alienante. Esta "pseudo-aura" se funda na dispersão. A mercadoria recompensa seus adoradores, distraindo-os (ROUANET, 1987). A mercantilização das manifestações culturais faz, dos bairros populares, espaços do "novo", instrumentalizados pela lógica do capitalismo, com a função de multiplicar produção e consumo para os moradores (e visitantes), modificando sua paisagem, a partir de ações externas, por intensificação da atividade turística - Ribeira e Curuzú - ou por exclusão do circuito turístico - Plataforma (CORDEIRO e SERPA, 2002; CORDEIRO, 2001):

A cultura da Península de Itapagipe está nos seus prédios, seus casarões, no convento de Mont Serrat. O chão do convento é todo de concha, uma coisa que nós esperamos colocar para visitação pública. As associações estão se empenhando para trazer turismo para Itapagipe. Nós estamos trabalhando com a Factur, ${ }^{22}$ fizemos uma grande pesquisa nessas igrejas todas para fazer o roteiro religioso. ${ }^{23}$

${ }^{18}$ Maria Olívia Fonseca do Espirito Santo, moradora do bairro do Curuzú.

19 João Carlos de São Pedro, morador do bairro da Ribeira.

${ }^{20}$ Existe um evento chamado Festa da Ribeira, no qual toda manifestação musical, folclórica desse bairro é manifestada, inclusive pessoas de fora vêm manifestar aqui a sua cultura e o que eles possam apresentar de novo aqui (João Carlos de São Pedro, morador do bairro da Ribeira).

21 "Decorrendo da devoção ao Senhor do Bomfim, no domingo, os romeiros vindos do Recôncavo, descalços, faziam um passeio pelos arredores de Itapagipe, freqüentando os estabelecimentos comerciais onde se abasteciam de comida e bebidas. Era uma espécie de Carnaval, não faltando os corsos de automóveis enfeitados com seus alegres passageiros metidos em vistosas fantasias. O ponto de concentração - a Ribeira - regurgitava de veranistas. As ruas se enchiam de vendedores. Em toda extensão do cais alinhavam-se saveiros vindos do Recôncavo, cheios de frutas das mais diversas qualidades. Blocos e mais blocos percorriam as ruas" (Jornal Bahia Hoje, 16/01/ 95).

\footnotetext{
${ }^{22}$ Faculdade de Turismo da Bahia.

${ }^{23}$ Terezinha Maria Paim Azevedo, moradora do bairro da Ribeira.
} 


\section{LAZER E DIVERSÃO COMO NEGAÇÃO DA CULTURA}

A desintegração da cultura é evidenciada através da conversão dos objetos culturais em mercadorias sociais, que podem circular e se converter em moeda de troca de toda espécie de valores, sociais e individuais (ARENDT, 2002):

Aqui tem o ensaio do llê, tem a sede do llê Aiyê, tem o bar de Bolachinha aqui no largo do Curuzú, você tem que andar pela rua direta do Curuzú, tem que passar por aqui para ver as pessoas, muita gente bonita, você vê muito universitários, muitos deputados, muitos estudiosos, pesquisadores, muitos visitantes estrangeiros que vêm aqui no Curuzú. ${ }^{24}$

Os produtos necessários à diversão servem ao processo vital da sociedade, servem para passar o tempo, um tempo onde não estamos totalmente libertos do processo vital e livres para o mundo da cultura. É um tempo de sobra, depois que trabalho e sono receberam seu quinhão (ARENDT, 2002):

Se você quer tomar uma cervejinha no final de semana e bater um bom papo você vem no bar de Nilson, se você quer conhecer um pouco mais da cultura afro, você vai aqui no llê Aiyê, se você quer se divertir no final de semana, bater um baralho, procura Bira, procura Dadai, procura Zinho, procura uma galera assim. $^{25}$

Mas, o divertimento, como o trabalho e o sono, constitui, irrevogavelmente, parte do processo vital biológico. O consumo e a recepção passiva do divertimento representam um metabolismo que se alimenta das coisas, devorando-as. Para Arendt (2002), os objetos culturais, cuja excelência é medida por sua capacidade de suportar o processo vital e de se tornarem pertences permanentes do mundo não deveriam ser julgados com padrões tais como "novidade" e "ineditismo". A necessidade de entretenimento começou a ameaçar o mundo cultural, pois os objetos culturais passaram a ser alterados para o consumo fácil, tornando-se "entretenimento" (Compare: ARENDT, 2002):

Os clubes fazem os bailes dançantes. É uma discoteca (música mecânica). São essas que estão na moda atualmente, é baile funk, pagode. Música da atualidade. Às vezes vêm bandas para tocar e às vezes é CD. ${ }^{26}$

A cultura relaciona-se com objetos e é um fenômeno do mundo, o entretenimento relaciona-se com pessoas e é um fenômeno da vida. A cultura é ameaçada quando todos os objetos ${ }^{27}$, produzidos pelo presente e pelo passado, são tratados como meras funções da sociedade, para satisfazer a alguma necessidade (ARENDT, 2002):

O meu grupo começou aqui mesmo, tocando em "barzinho", aí com esse negócio da mídia de pagode toda hora, foi juntando um daqui, outro dali e aí começamos a formar bandas. Eu acho que as pessoas daqui da Ribeira não têm muita opção. Não têm o dinheiro de transporte para ir para a Orla, é longe, o ingresso é caro, $R \$ 30,00$ a $R \$ 40,00$, e aqui você tem a opção de não pagar nada. O custo da pessoa que está colocando a gente para tocar aqui é baixo. Quando se faz esse tipo de show, tira gente da marginalidade; tem muita criança mesmo que curte, que gosta, tira o menino da rua e eu acho isso importante. Qualquer tipo de trabalho é importante, ainda mais na área de cultura, para você ver, estudar, cantar, dançar... ${ }^{28}$

\section{CULTURA DE MASSA E SUBCULTURAS}

Segundo ARENDT (2002), a expressão "cultura de massa" origina-se de outra, não muito mais antiga, "sociedade de massa", e evidencia o relacionamento altamente problemático entre sociedade e cultura. A "sociedade de massa" sobrevém quando a massa da população se incorpora à sociedade, com a eliminação de instâncias mediadoras. Sociedade de massa e cultura de massa parecem ser fenômenos inter-relacionados, porém seu denominador comum não é a massa, mas a sociedade onde as massas foram incorporadas. A autora aponta ainda um antagonismo entre sociedade e cultura que é anterior à ascensão da sociedade de massa: o monopólio da cultura pela sociedade, em função de seus objetivos próprios, tais como posição social e status, evidenciando o caráter objetivo do mundo cultural, na medida que este contém coisas tangíveis, compreende e testemunha todo o passado registrado da humanidade (Compare: ARENDT, 2002).

${ }^{24}$ Antônio Carlos (Vovô), presidente do bloco afro llê Aiyê.

${ }^{25}$ Renivaldo Santana Sena (vulgo Reni), morador do bairro do Curuzú.

${ }^{26}$ Ronaldo Antônio da Conceição, morador do bairro de Plataforma.

${ }^{27}$ Obras de arte não são fabricadas para os homens, mas antes para o mundo, que está destinado a sobreviver ao período de vida dos mortais, ao ir e vir das gerações (compare: ARENDT).

${ }^{28}$ Dalmiro da Silva Costa Filho (vulgo Gal), morador do bairro da Ribeira. 
Com as leis do mercado penetrando na substância dos objetos culturais e tornando-se imanentes a eles como leis estruturais, tudo - difusão, escolha, apresentação e criação - se orienta, nos setores amplos da cultura, de acordo com estratégias de venda do mercado:

A cultura de massas recebe o seu duvidoso nome exatamente por conformar-se às necessidades de distração e diversão de grupos de consumidores com um nível de formação relativamente baixo, ao invés de, inversamente, formar o público mais amplo numa cultura intata em sua substância (HABERMAS, 1984, p. 195). ${ }^{29}$

Em Salvador, o processo de folclorização da maioria das festas populares segue o caminho da "retradicionalização" ou da "modernização" por intervenção direta do mercado ou do "Estado-Espetáculo". "É possível que no futuro todas as manifestações populares da Bahia estejam estatizadas" (ALBERGARIA, 2003, p. 7), preservadas ou resgatadas "pelos cuidados da Emtursa $^{30}$ e Bahiatursa ${ }^{31}$ " (ALBERGARIA, 2003).

A Bahia e sua capital transformam-se em produtos turístico-publicitários, com a distribuição desigual e segregadora de equipamentos culturais no tecido urbano-regional. Assistimos à emergência de "novas" tradições reinventadas a cada dia para um consumo turístico cada vez mais segmentado e diferenciado:

Na festa da Ribeira, o pessoal da Ribeira mesmo foge, já não participa mais, vai para a ilha, fecha sua casa... Porque é muita desordem, muita violência. Na parte física do bairro, a única coisa que muda é que a prefeitura se movimenta um pouco pra limpar a rua, pra lavar, pra passar no meio-fio aquela tinta branca, botar luzes, as gambiarras e as barracas que colocam pra vender bebidas, comidas, essas coisas. Aí fica um clima de festa mesmo, festa de largo. Acho que não muda nada, depois que passa, volta tudo ao normal. ${ }^{32}$

É um consumo de classes médias urbanas com "capital escolar" elevado, norteado por uma "conduta de acumulação", baseada, sobretudo, na sensação da "descoberta". Busca-se tudo aquilo que pode ser assimilado nas tradições locais e regionais, a fim de confirmar sua própria identidade cultural de classe. É uma lógica homogeneizante, que exprime uma posição "de força", afirmando a universalidade dos valores culturais das classes médias urbanas, se apropriando de tudo que parece digno de ser extirpado das classes populares, num processo de "vampirismo cultural". $\mathrm{Na}$ verdade, os "clientes" privilegiados dos equipamentos $\mathrm{e}$ objetos culturais, que são as classes média cultivadas, concebidos por elas e para elas, garantem, através da apropriação, sua identidade e seu poder (BALLION, AMAR e GRANDJEAN, 1983).

Vista neste contexto, a atividade turística faz com que as populações locais reinventem seu cotidiano e, nesta reinvenção, a lógica da atividade turística se sobrepõe às tradições locais e à própria identidade da comunidade, impactada por novos valores, novos símbolos, novas referências e expectativas (FONTELES, 1999). São valores hegemônicos, já que são impostos por grupos sociais específicos com suas concepções próprias de "cultura":

Todo final de semana, a partir de sexta-feira, saem inúmeras escunas daqui para todo o arquipélago de ilhas da Baía de Todos os Santos. Saem escunas daqui para Ilha de Maré, Madre de Deus, Ilha dos Frades ou Ilha de Itaparica. Inclusive tem escunas daqui que vão direto para Morro de São Paulo, dependendo do contrato do aluguel da escuna. Inclusive Xuxa e outros artistas já estiveram aqui para fazer passeios. ${ }^{33}$

O incremento da atividade turística mostra também diferenças no interior dos bairros pesquisados, quanto à incorporação seletiva de algumas áreas pelo turismo. Geralmente a localização da infra-estrutura também é diferenciada, privilegiando estas áreas, que coincidem muitas vezes com os núcleos históricos dos bairros, mais consolidados e com população com maior poder aquisitivo. Essa imagem "histórica", cooptada pelo marketing turístico, é "interiorizada" na percepção dos moradores, mesmo daqueles que não moram nas áreas com maior potencial turístico, que acabam por reproduzir uma "representação hegemônica", estilizada, dos bairros onde moram (SERPA, 2001):

29 "Caso seja permitida uma generalização, as camadas de consumidores em que novas formas de cultura penetram não pertencem nem à camada tradicionalmente culta nem às camadas sociais inferiores, mas com uma certa freqüência a grupos em processo de ascensão, cujo status ainda necessita de legitimação cultural. Intermediado por esse grupo inicial, o novo meio se expande então, no entanto, primeiro dentro do estrato social mais alto para, a partir daí, propagar-se pouco a pouco para os grupos de status inferior" (HABERMAS, op. cit., p. 205-206).

${ }^{30}$ Empresa Municipal de Turismo do Salvador.

31 Órgão estadual de turismo.

32 Cleonice Simões Coelho dos Santos, moradora do bairro da Ribeira.

${ }^{33}$ João Carlos de São Pedro, morador da Ribeira, explicando os referenciais do bairro que indicou no mapa mental solicitado durante a entrevista. 
Eu gosto muito do bairro da Ribeira, porque eu nasci aqui, eu me criei aqui, conheço tudo... e eu caminho todas as manhãs: eu faço uma caminhada daqui até o Bomfim, tem vezes que eu prolongo e vou até a Boa Viagem, eu gosto muito de caminhar pelo bairro, durante as caminhadas eu vejo o mar, as pessoas praticando esporte, porque aqui as pessoas praticam muitos esportes na praia, tem também muitas mães que vão passear com seus filhos bebês. ${ }^{34}$

Gradativamente, uma concepção burguesa da vida, fundada no primado do indivíduo racional e prag-mático, legitimador do individualismo como fundamento da vida social, ganhou curso no âmbito dessas mesmas práticas (SEABRA, 2003, p. 230).

As práticas sociais às quais se refere Seabra representavam, na vida do bairro do Limão, em São Paulo, diferentes visões sociais do mundo, marcadas por fortes continuidades históricas. Essas práticas vão sendo modificadas à medida que o desenvolvimento do mundo do trabalho criou as condi-ções necessárias para liberar o homem, enquanto indivíduo, "das peias da sociedade tradi-cional", baseada nos valores da família e da religião (Compare: SEABRA, 2003).

Para BOURDIEU (1979), o habitus é ao mesmo tempo um princípio gerador de práticas sociais e um sistema de classificação dessas práticas. É da relação dessas duas características que definem o habitus capacidade de produzir práticas e objetos passíveis de classificação e capacidade de apreciar e diferenciar essas práticas e objetos (gosto) - que se origina o mundo social das representações, o espaço dos estilos de vida. O habitus é estrutura estruturante, que organiza as práticas e a percepção das práticas, mas também estrutura estruturada, produto da divisão em classes sociais. Cada posição/condição é definida por suas propriedades intrínsecas, mas também por suas propriedades relacionais em um sistema de diferenças, de posições diferenciais, por tudo aquilo que ela não é, tudo que a distingue e que a opõe a outras posições/ condições (Compare: BOURDIEU, 1979).

Em matéria de consumo cultural a oposição principal se estabelece entre o consumo de bens distintos e vulgares. O verdadeiro princípio gerador das diferenças no âmbito do consumo é a oposição entre gostos de luxo (ou de liberdade) e os gostos de necessidade. Os primeiros são próprios dos indivíduos que são produto de condições materiais de existência, definidas pela distância à necessidade, pela liberdade, pelas facilidades asseguradas pela possessão de um capital; os segundos exprimem as necessidades, das quais eles são produto. Não satisfeitas de não possuírem nenhum conhecimento valorizado pelo "mercado de exames escolares" ou pelas "conversações eruditas", de não possuírem nada além de técnicas e conhecimentos não valorizados por esse mercado, as classes populares são aquelas que sacrificam a maior parte de sua renda à alimentação, aquelas que gastam menos com roupas e higiene pessoal, que se entregam aos lazeres pré-fabricados em sua intenção pelos "engenheiros da produção cultural de massa" (Compare: BOURDIEU, 1979).

O estudo de Bourdieu sobre a distinção social cobriu uma lacuna no tocante ao estudo das subculturas das classes sociais, estabelecendo um contraste entre o habitus das classes médias e das classes populares. Na visão de BURKE, 2002), no entanto, o autor não discutiu a importância dessa diferença à

(digamos) diferença entre os franceses e seus vizinhos. É bem possível que quantificar tais diferenças seja uma tarefa inviável. A um nativo de um determinado país, os contrastes culturais entre classes sociais diferentes podem muito bem parecer esmagadores, ao passo que uma pessoa de fora observa em primeiro lugar o que elas têm em comum (BURKE, 2002, p. 174-175).

Por outro lado, Burke reconhece que o estudo das subculturas tenha algo valoroso a acrescentar ao estudo histórico e sociológico das classes sociais.

\section{APROXIMANDO A LENTE DAS SUBCULTURAS NOS BAIRROS POPULARES...}

O resgate da história oral dos bairros populares de Salvador, das diferentes visões de mundo e de "espaços vividos" mostra que há muitos bairros, muitas Plataformas e Ribeiras, muitos Curuzús... Descobre-se que os bairros são culturas transversais, que abarcam muitas e múltiplas subculturas: "da pesca", "do remo", "jovem", "negra", "capoeirista", "afro-brasileira" ou

\footnotetext{
${ }^{34}$ Mauritânia Macedo Teixeira, moradora da Ribeira, explicando o que motiva seus percursos a pé pelo bairro. Ao ser questionada sobre os limites do mesmo, procura incluir sua residência na "Ribeira", embora more distante da orla do bairro: Olha, geograficamente, na minha opinião, começaria ali no Papagaio e vinha pela parte de fora e envolvia toda essa península aqui até a Sorveteria da Ribeira, a lgreja da Penha. Antigamente não tinha aquela parte de lá da cidade baixa. Há uns 15 anos atrás, o governo fez um aterro e emendou com a Massaranduba e aí foi formando a Mangueira, o Areal. Aí, identifica tudo isso como Ribeira, entendeu? Mas foi uma coisa que cresceu. Tem a parte daqui e a parte de lá. Vamos dizer que tem classes sociais diferentes: tem a média, tem a alta e tem a baixa.
} 
"bairrista"; o outro lado da moeda traz para dentro dos bairros o mundo e suas subculturas: "turística", "patrimonialista" ou "conservacionista" (BRITO e SERPA, 2004). Mas como estudar essas subculturas?

Uma pista interessante vem das pesquisas de Cosgrove em geografia cultural. Para o autor, o poder é expresso e mantido na reprodução da cultura, havendo culturas dominantes e subdominantes ou alternativas, não apenas no sentido político, como também em termos de sexo, idade e etnicidade. As culturas subdominantes podem ser classificadas, sob essa ótica, como residuais (que sobram do passado), emergentes (que antecipam o futuro) e excluídas (que são ativa ou passivamente suprimidas): "Cada uma destas subculturas encontra alguma expressão na paisagem, mesmo se apenas numa paisagem de fantasia" (Compare: COSGROVE, 1998, p. 92-123).

Vista assim, a questão das subculturas aponta, nos bairros pesquisados, para a importância da questão étnica e para inúmeras tentativas de afirmação de uma identidade afro-brasileira, especialmente nos bairros de Plataforma e Curuzú. O depoimento da moradora de Plataforma, Joseane Santos da Cruz, esclarece porque a capoeira é tão citada pelos moradores; segundo ela, essa manifestação é uma representação da cultura baiana, de modo que a Ampla - Associação dos Moradores de Plataforma, procurando resgatar e preservar esta cultura, configura o bairro como sendo mais um espaço desta preservação (CORDEIRO e SERPA, 2002; CORDEIRO, 2001):

Eu acho que existe um esforço da comunidade, ela tenta implantar uma cultura. Hoje, a gente, morador do bairro, investiu na capoeira... A capoeira é uma cultura dos nossos antepassados, cabe a nós ir resgatando. Esse grupo dentro da Ampla tem oito anos, mas a capoeira dentro do bairro existe há muito tempo.

Na maioria das vezes, é no espaço das Associações de Moradores, ${ }^{35}$ que essas subculturas encontram algum espaço de expressão. Na Ampla, além do grupo de capoeira, outras iniciativas vão surgindo, todas na direção de resgatar a auto-estima da comunidade:

O samba-de-roda ${ }^{36}$ e o maculêlê ${ }^{37}$ também ainda estão presentes aqui na periferia, as pessoas tentam praticar. O mesmo professor que veio desen-volver o trabalho da capoeira criou o grupo de maculêlê no bairro de Plataforma e a gente atende a uma demanda muito grande de pessoas que querem se ligar ao traba-lho do maculêlê e do samba-de-roda. ${ }^{38}$

No Curuzú, esse trabalho, baseado no resgate da cultura afro-brasileira, é realizado por alguns terreiros e pelo bloco afro Ilê Aiyê: "O terreiro Vodum Zô é um lugar ótimo para conhecer a capoeira e o maculêlê, a sede do llê também tem várias opções, tem a capoeira, o maculêlê também". ${ }^{39}$

Ao mesmo tempo, muitas dessas manifestações vão desaparecendo, permanecendo vivas apenas na memória de alguns moradores: "No passado tinha baile pastoril, tinha um bloco africano do Jorge Careca, tinha aquelas festas de São João, hoje em dia não tem mais". ${ }^{40}$ Nas entrevistas com os moradores, é recorrente a idéia de que as manifestações culturais nos bairros eram mais ricas e diversificadas no passado:

As manifestações que existiam no passado, não existem mais, tinha bailes pastoris, que a gente até pouco tempo queria revitalizar. Aqui existia o carnaval, Piró e Zé Quatro faziam os bailes de carnaval e era na rua, minha tia Biloca fazia as máscaras, tinha quadrilha de São João, na páscoa tinha queima de Judas, tinha ciranda, mas tudo isso se perdeu, hoje não tem mais nada. ${ }^{41}$

Pode-se dizer, retomando-se as assertivas de COSGROVE,1998, que o resgate de algumas subculturas residuais (ou mesmo excluídas) e sua transformação em emergentes, vai aos poucos impregnando a vida dos bairros pesquisados, reafirmando e transformando valores do passado e deflagrando novos - ou renovados - processos identitários: ${ }^{42}$

${ }^{35}$ Tem uma associação chamada AMAI - Associação de Moradores e Amigos de Itapagipe que trabalha com capoeira, que faz esse tipo de trabalho com maculêlê, capoeira e música (Dalmiro da Silva Costa Filho, morador do bairro da Ribeira).

${ }^{36}$ Denominação do samba baiano.

${ }^{37}$ Maculêlê: Misto de jogo e dança de Bastões, de Santo Amaro, no Recôncavo Baiano.

38 Joseane Santos da Cruz, moradora do bairro de Plataforma.

${ }^{39}$ Alexandra Silva Moreira, moradora do bairro do Curuzú.

40 Hilda de Jesus Santos (Mãe Hilda Jitolu), moradora do bairro do Curuzú.

${ }^{41}$ Valdíria Lopes, moradora do bairro do Curuzú.

42 "A identidade como fundante gera a desigualdade, possibilitando um processo político que se caracteriza pela luta por uma hegemonia universal (...) A diferença como fundante gera, em potência, a igualdade, possibilitando um processo político que se caracteriza por hegemonias localizadas, múltiplas e instáveis, o que gera a necessidade de conviver com múltiplas subjetividades e vivenciar múltiplos contextos, pois originalmente somos iguais na diferença em potência (...) Identidade e diferença não estão no mesmo universo; se a identidade é fundante, em potência, a diferença é um dado da realidade, constituída como precipitação dos acontecimentos. Se, no entanto, a diferença é fundante, em potência, a realidade é constituída por processos identitários decorrentes da precipitação dos acontecimentos" (SERPA, 2004, p. 166-167). 
Hoje o llê Aiyê tem um papel fundamental para a construção do movimento cultural dentro do Curuzú, eu tenho certeza que é a maior referência do bairro, principalmente porque a maioria da população é negra, então houve uma mudança, hoje a gente está dentro de um bairro periférico e possuímos uma estrutura muito forte que é a Senzala do Barro Preto, ${ }^{43}$ então hoje esses movimentos vão poder divulgar seu trabalho numa área própria, o Curuzú. ${ }^{44}$

No Curuzú, são notáveis os aspectos culturais que demonstram sua forte ligação com as tradições afrobrasileiras. As manifestações culturais "emergentes", relacionadas com a atuação de terreiros de candomblé e do bloco llê Aiyê, tornam-se, gradativamente, hegemônicas no bairro. Elas só podem ser consideradas "emergentes" vistas no contexto da cidade, como afirmação da cultura negra numa metrópole desigual e segregacionista (SOUZA e SERPA, 2004).

Processos identitários podem surgir também a partir da relação original entre a sociedade e a natureza, redundando em atividades que aos poucos vão marcar um estilo de vida característico de alguns bairros da cidade. O mar tem lugar de destaque, por exemplo, na relação entre os moradores e o bairro da Ribeira, marcando sua vida cultural, como nas disputadas regatas, nas atividades pesqueiras, nos festejos e nas lavagens que aliam à festa popular a religiosidade de católicos e adeptos dos cultos afro-brasileiros (COELHO e SERPA, 2001). As regatas ${ }^{45}$ aparecem com certo destaque no depoimento dos moradores entrevistados: "Até hoje nós temos regatas. Duram apenas um dia e ocorrem no Tainheiros; vêm do Mont Serrat pra cá. Antigamente nós tínhamos torcidas. Hoje não tem mais a torcida, mas tem muita gente que vem apreciar". ${ }^{46}$

Na Ribeira há pessoas, como Silvio Santos Silva ${ }^{47}$ que "dormem e acordam pensando em remo":

No momento, a Regata é o evento público mais prestigiado e esperado pelo pessoal. Esporte também é cultura. A gente está batalhando para erguer o Clube Santa Cruz. Foi o clube que me deu oportunidade, que me respeita como pessoa e como profissional.
Eu sou o único profissional especializado que trabaIha com barco de fibra de vidro na Bahia.

Para ele, o remo já foi um esporte de elite: "o pessoal do meu nível não tinha condição de praticar, porque na época tinha que pagar uma mensalidade para remar. Hoje em dia é o contrário, o clube é quem arca com as despesas do profissional."

Se podemos inferir que as regatas enquanto uma subcultura residual reafirma-se no cotidiano do bairro da Ribeira como "emergente", o mesmo não pode ser dito com relação à pescaria e à mariscagem. Em Plataforma, a pesca se descaracterizou bastante nos dias atuais, tendo sido citada por apenas um morador, que, por sua vez, é pescador. A atividade pesqueira aparece na imprensa escrita apenas em função da mariscagem ainda praticada no bairro. Plataforma, no entanto, tem muitos pescadores que ainda sobrevivem da pesca. Todavia, a Festa dos Pescadores ${ }^{48}$ não recebeu nenhum registro da imprensa escrita nas últimas duas décadas. Uma manifestação conseqüentemente segue a trilha da outra, num efeito dominó, visto que seu grupo representante também se encontra enfraquecido (CORDEIRO e SERPA, 2002).

\section{À GUISA DE CONCLUSÃO: OS BASTIDORES DAS "SUBCULTURAS EMERGENTES" - “RETRADICIONALIZAÇÃO” DA EXPERIÊNCIA?}

A análise das subculturas emergentes apontadas anteriormente mostra, no caso do bairro do Curuzú e do bloco llê Aiyê, uma revalorização da experiência, no sentido indicado por BENJAMIN (1996), baseada numa filosofia do tribalismo e numa visão coletivista. Para DANTAS (1996), a liderança de Antônio Carlos dos Santos, o Vovô do llê proporcionou uma nova significação para a comunidade negra baiana:

A ressonância de sua visão de agrupamento da população negra em torno de um discurso ideológico uno iria remeter a símbolos importantes da ances-

${ }^{43}$ Denominação da sede do llê Aiyê, no bairro do Curuzú.

${ }^{44}$ Ramnsés Santos dos Santos, morador do bairro do Curuzú.

45 "As regatas sempre foram disputadas no Tainheiros, participando quatro clubes. A sede do Itapagipe sempre foi aqui mesmo, a do Santa Cruz, na Calçada, do São Salvador, na praia de São Joaquim e a do Vitória, no Farol. Assistir às regatas era uma diversão emocionante, tanto pelo visual que os barcos nos proporcionavam, como pela febre da torcida. Em 2 de abril de 1905, a Federação realizou a primeira regata. A segunda regata ocorreu em 2 de outubro de 1905, quando foi instituída a taça Olga, pelo São Salvador. Às regatas, os homens compareciam com cartola e as mulheres usando chapéu, todos muito elegantes" (BORGES, 2001, p. 77-79).

${ }^{46}$ Cleonice Simões Coelho dos Santos, moradora do bairro da Ribeira.

${ }^{47}$ Praticante de remo, morador do bairro da Ribeira.

48 "Sempre tem a festa de pescadores lá na Igrejinha. Tem queima de foguetes e tem um pessoal trazendo a imagem da igreja dali de baixo e aí tem a festa. Tem música ao vivo, pagode, sempre com uma banda que às vezes é daqui e às vezes de fora. Essa festa acontece em 28 de junho todo ano" (Nelvian de Souza, morador do bairro de Plataforma). 
tralidade negra, como os quilombos ou mesmo os reinos tribais da África medieval. A relação do líder com os rituais de candomblé, por outro lado, trar-lhe-ia uma legitimidade hierárquica quase mítica no grupo" (DANTAS, 1996, p. 158).

O llê Aiyê vem firmando desde então parcerias e patrocínios com empresas como a Petrobrás, os Supermercados Extra, a Schincariol e a Claro, de telefonia celular, que patrocinam o Camarote do llê, na Praça Castro Alves (centro de Salvador), durante os dias de Carnaval. Outras parcerias, com o BNDES, a Eletrobrás e a Petrobrás, viabilizaram a construção da nova sede do bloco, a Senzala do Barro Preto, no bairro do Curuzú. O prédio, inaugurado em novembro de 2003, tem oito andares, com cinco mil metros quadrados de área construída, incluindo área de eventos para quatro mil pessoas, estúdio, restaurante, escolas formais, de dança, de percussão e profissionalizante, espaço para ensaio da Banda Erê e cozinha-escola (Jornal A Tarde, 22/2/2004, p. 3).

Raciocinando ainda nos termos de BENJAMIN (1996), observamos, por outro lado, que o "valor de exposição" das manifestações afro-brasileiras, no caso do llê Aiyê, coloca em risco seu "valor de culto" original e as possibilidades de resgate da memória coletiva através da cultura. O que significa, afinal, o impacto, na vida do bairro, de quatro mil visitantes nos ensaios do bloco? Não estaríamos assistindo mais uma vez a um processo de superposição da vivência à experiência, detectado por BENJAMIN (1996) na percepção do homem moderno, quando da consolidação do capitalismo nas grandes cidades? Afinal, o processo de "retradiciona-lização" das manifestações culturais nos bairros populares de Salvador não estaria transformando cultura em lazer e diversão, ao "devorar os objetos do mundo" e transformá-los em "mercadorias", como pressupõe ARENDT (2002)?

Esse parece ser o caso também da "revitalização" das regatas no bairro da Ribeira. A polêmica em torno do fechamento das casas de bingo em Salvador tem sido motivo de preocupação entre os atletas e os dirigentes dos clubes de remo, que se reuniram em março de 2004 para discutir o assunto na Federação dos Clubes de Regatas da Bahia (FCRB). As casas patrocinavam a prática do remo na capital, destinando $\mathrm{R} \$$ oito mil por mês à entidade desportiva. $\mathrm{O}$ dinheiro era dividido em partes iguais, entre a Federação e os quatro clubes da capital, entre eles o Santa Cruz, com sede em Itapagipe. O clube, que comemorou em 2004 cem anos de fundação, pode ter seus projetos comprometidos sem o dinheiro dos bingos. Apesar da estrutura danificada, com apenas dois barcos de competição, o clube investe na construção de barcos novos e na formação de novos atletas, jovens carentes da Península Itapagipana (Jornal A Tarde, 4/3/2004, p. 6).

Vemos, portanto, que as regatas vão adquirindo e consolidando uma "exponibilidade" que se transforma em capital e investimento, tornando-se, ao mesmo tempo, cada vez mais dependentes de empresas patrocinadoras. É o mercado quem vai ditar em última instância quais manifestações culturais devem ser "revitalizadas" ou "retradicionalizadas", afastando-as gradativamente do seu sentido e valor de culto originais e transformando, nesse processo, a experiência e a memória dos envolvidos em vivência e mercadoria, a ser consumida como objetos de marketing empresarial ou turístico.

O Sebrae, em parceria com o llê Aiyê e a Associação de Moradores e Amigos do Curuzú - AMAC quer viabilizar, por exemplo, um corredor cultural na rua principal do bairro, que dá acesso à sede do bloco famoso. Aidéia é capacitar os comerciantes locais, para melhor atender aos visitantes. O risco - sempre presente em projetos assim - é a criação de mais um "shopping center a céu aberto", descontextualizado da realidade local, como já ocorreu inúmeras vezes em Salvador e no Estado da Bahia. O risco é um "Curuzú embrulhado para presente", distanciado da experiência dos moradores e das tradições enraizadas na história do lugar.

Se a cultura de massa e suas subculturas - "do automóvel", "da televisão", "dos supermercados”, "do transporte coletivo", etc. - são tidas como standardizadas, geralmente descritas como rudimentares, conformistas e alienantes, elas são também, por outro lado, estruturas transversais de organização, originando "efeitos de massa" característicos (BALLION, AMAR e GRANDJEAN, 1983). Diferenças de classe e mesmo diferenças individuais podem ser minimizadas ou mesmo ocultadas por estes "modos de ser" dominantes. A questão fundamental é saber até que ponto as subculturas emergentes nos bairros populares das cidades contemporâneas podem fazer frente às subculturas de massa, originando novas e renovadas transversalidades, baseadas na experiência dos moradores, em última instância os verdadeiros agentes de transformação desses espaços. 


\section{REFERÊNCIAS}

ALBERGARIA, Roberto. Festas populares baianas: pós-modernização ou retradicionalização? Jornal A Tarde, 4 dez. 2003. Caderno 1, p. 7.

ARENDT, Hannah. Entre o passado e o futuro. 5. ed. São Paulo: Perspectiva, 2002. Coleção Debates/Política

BALLION, Robert;AMAR, Laure; GRANDJEAN, Alain. Le Parc de la Villette - Un espace public à inventer. Paris: Laboratoire d'Économétrie de l'École Polytechnique/CNRS, 1983.

BENJAMIN, Walter. Obras Escolhidas I - Magia e Técnica, Arte e Política / Ensaios sobre Literatura e História da Cultura. 7. ed. São Paulo: Brasiliense, 1996.

BORGES, Jafé. (Org.). Salvador era assim. Salvador: Instituto Geográfico e Histórico da Bahia, 2001.

BOURDIEU, Pierre. La distinction - Critique sociale du jugement. Paris: Les Éditions de Minuit, 1979.

BRITO, Marcelo Sousa; SERPA, Angelo. Percepção e cultura na periferia de Salvador: o bairro em imagens, uma experiência de ensino, extensão e pesquisa. In: CONGRESSO BRASILEIRO DE EXTENSÃO UNIVERSITÁRIA, 2., 2004, Belo Horizonte. Anais... Belo Horizonte: UFMG, 2004.

BURKE, Peter. História e teoria social. São Paulo: UNESP, 2002.

COELHO, Suely dos Santos.; SERPA, Angelo. Transporte coletivo nas periferias metropolitanas: estudos de caso em Salvador, Bahia. Geografia, Rio Claro, SP: Associação de Geografia Teorética, v. 26, n. 2, p. 91-126, ago. 2001.

CORDEIRO, Márcia de Freitas. Bairro e identidade cultural na periferia de salvador. Salvador: PIBIC/CNPq, UFBA, 2001. Relatório final de pesquisa.

CORDEIRO, Márcia de Freitas; SERPA, Ângelo. Bairro e identidade cultural na periferia de Salvador. In: SEMINÁRIO DE PESQUISA E PÓS-GRADUAÇÃO/XX SEMINÁRIO ESTUDANTIL DE PESQUISA, 2., 2002, Salvador. Resumos. Salvador: Pró-Reitoria de Pesquisa e Pós-Graduação,. v. 1, p. 234-234.

COSGROVE, Denis. A geografia está em toda parte: cultura e simbolismo nas paisagens humanas. In: CÔRREA, Roberto Lobato; ROSENDAHL, Zeny. Paisagem, Tempo e Cultura. Rio de Janeiro: EDUERJ, 1998.

DANTAS, Marcelo. Gestão, cultura e leadership - o caso de três organizações afro-baianas. In: FISCHER, Tânia. (Org.). Gestão contemporânea - cidades estratégicas e organizações locais. Rio de Janeiro: Fundação Getúlio Vargas, 1996.

FONTELES, José Osmar. Comunidade de pescadores de Jericoacara-Ceará entra na rota turística. In: VASCONCELOS, Fábio Perdigão. (Org.). Turismo e Meio Ambiente. Fortaleza: Funece/Universidade Estadual do Ceará, 1999.

HABERMAS, Jürgen. Mudança estrutural da esfera pública. Rio de Janeiro: Tempo Brasileiro, 1984.
HAESBAERT, Rogério. Des-territorialização e identidade. Niterói: EDUFF, 1997.

KELLER, Suzanne. El vecindário urbano: una perspectiva sociológica. 2. ed. México: Siglo XXI, 1979.

LYNCH, Kevin. A imagem da cidade. Rio de Janeiro: Edições 70, 1990.

RELPH, Edward. As bases fenomenológicas da geografia. Geografia, Rio Claro-SP: Associação de Geografia Teorética, v. 4, n. 7, p. 1-25, abr. 1979.

ROUANET, Sérgio Paulo. Do trauma à atrofia da experiência. In: Édipo e o Anjo: itinerários freudianos em Walter Benjamin. Rio de Janeiro: Tempo Brasileiro, 1987.

SANTOS, José Luiz dos. O Que é Cultura. 7. ed. São Paulo: Editora Brasiliense, 1988. Coleção Primeiros Passos.

SEABRA, Odete Carvalho de Lima. Urbanização e Fragmentação - Cotidiano e vida de bairro na metamorfose da cidade em metrópole, a partir das transformações do Bairro do Limão. São Paulo, 2003. Tese (Livre Docência) Universidade de São Paulo.

SERPA, Angelo. Percepção e Fenomenologia: Em busca de um método humanístico para estudos e intervenções do/no lugar. Olam - Ciência e Tecnologia, Rio Claro, v. 1, n. 2, p. 2961, 2001.

SERPA, Angelo.; GARCIA, Antonia dos Santos. O Potencial Turístico do Subúrbio Ferroviário de Salvador sob a Ótica dos Moradores. In: LIMA, Luiz Cruz. (Org.). A diversidade do saberfazer turístico. Fortaleza: FUNECE, 1999.

SERPA, Felippe. Rascunho digital. Diálogos com Felippe Serpa. Salvador: EDUFBA, 2004.

SOUZA, Flávia Silva de. Identidade de bairro e manifestações culturais em áreas de urbanização popular de salvador: estudos de caso nos bairros do Curuzú e São Tomé de Paripe. Salvador: PIBIC/CNPq, UFBA, 2004. Relatório final de pesquisa.

SOUZA, Flávia Silva de; SERPA, Angelo. Identidade de bairro e manifestações culturais em áreas de urbanização popular de salvador: estudo de caso no Curuzú. In: SEMOC SEMANADE MOBILIZAÇÃO CIENTÍFICA, 7., 2004, Salvador. Anais... Salvador: UCSAL, 2004.

SOUZA, Marcelo José Lopes de. O bairro contemporâneo: ensaio de abordagem política. Revista Brasileira de Geografia, Rio de Janeiro, v. 51, n. 2, p. 139-172, abr./jun. 1989.

TUAN, Yi-Fu. Espaço e lugar. São Paulo: DIFEL, 1983.

VILASSANTE, Tomás. Metodologia dos conjuntos de ação. In: COLÓQUIO SOBRE PODER LOCAL, 6., 1996, Salvador. Anais... Salvador: Núcleo de Pós-Graduação em Administração, 1996. p. 129-142. 
SERPA, A. Experiência e vivência, percepção e cultura: uma abordagem...

\section{MATÉRIAS E REPORTAGENS}

"É dia de festa na Ribeira". Jornal Bahia Hoje. Salvador, 16 jan. 1995. Primeiro Caderno

"Liderança com toques de ousadia". Jornal A Tarde. Salvador, 22 fev. 2004. Caderno Emprego \& Mercado.
“Azar na Regata”. Jornal A Tarde. Salvador, 4 mar. 2004. Caderno Esporte Clube. 